\title{
Introduction to the minireviews series on mitochondrial matters in amyotrophic lateral sclerosis, Lou Gehrig's disease
}

\author{
George H. Sack Jr.
}

Published online: 8 December 2011

(C) Springer Science+Business Media, LLC 2011

\section{Introduction}

Who was Henry Louis Gehrig? "Lou" Gehrig (Fig. 1) was one of the all-time "great" baseball players. His retirement from the New York Yankees in 1939 gave prominence and notoriety in America to the neurologic disorder that still is associated with his name. His retirement, after playing in 2,130 consecutive games was a national event; he died 2 years later at the age of 37 . Despite its prominent eponymic association with Gehrig in America, the condition had been recognized previously and was most prominently described by Charcot in France.

Gehrig's presentation and clinical course were typical of the disorder now known as amyotrophic lateral sclerosis or ALS. In his case, it began with reduced muscle strength and difficulties running that moved relatively rapidly to generally reduced muscle strength. ALS usually begins with difficulties with fine movements and reduced motor strength, often in the hands. The progression extends to the arms and usually to the legs. Associated with increased tendon reflexes, there is no sensory component to the clinical picture. Involvement of the muscles of the oropharynx and tongue can cause poor speech articulation and problems with swallowing. Although Gehrig was relatively young, about $10 \%$ of patients develop symptoms before 40 years of age. As with Gehrig, reduced function generally leads to death in 2-3 years. No treatment is available and the disorder has been discussed as a justification for assisted suicide (Ganzini et al. 1998).

\section{G. H. Sack Jr. $(\bowtie)$}

Departments of Medicine and Biological Chemistry,

The Johns Hopkins University, School of Medicine,

Baltimore, MD 21205, USA

e-mail: gsack@jhmi.edu
ALS is not uncommon (an Italian study - Piemonte and Valle d'Aosta - gave an incidence of 2.5/100,000 [2001]) and large clinical studies have dissected its clinical manifestations. In general it is a strictly motor neuron disorder. Pathologic changes include loss of neurons in the anterior horns of the spinal cord and motor nuclei of the lower brainstem (larger neurons are generally affected earlier). In studies of large clinical populations it became clear that subsets of individuals cluster in families and several extensive pedigrees have been identified.

Inheritance patterns are varied in ALS populations but the most prominent transmission pattern is autosomal dominant and is seen in about $10 \%$ of families (FALS1 OMIM \# 105400). In 1991 Siddique et al. (1991) demonstrated linkage of FALS1 to chromosome 21 markers and Rose et al. (1993) found multiple heterozygous mutations in the gene for superoxide dismutase 1 (SOD1) in 13 different families (site 21q22.11). Later, Andersen et al. (1995) found other SOD1 mutations in affected individuals in a homozygous pattern (their populations included families with consanguinity). Although multiple mutations have been identified, Cudkowicz et al. (1997) found the $\mathrm{A} 4 \mathrm{~V}$ mutation in $50 \%$ of affected kindreds in a large study.

Other genes have been associated with the clinical picture of ALS. Elden et al. (2010) found an association between intermediate-length expansions (27-33) of a polyglutamine repeat in Ataxin1 in some individuals (longer expansions correlated with spinal cerebellar ataxia type 2). Further clinical dissection of affected individuals has implicated other loci but none has reached the frequency of the SOD1 data and at least some of the other types are likely different disorders sharing myopathic features. For example, a distinctly different disorder often includes ALS-type myopathy with frontotemporal dementia 


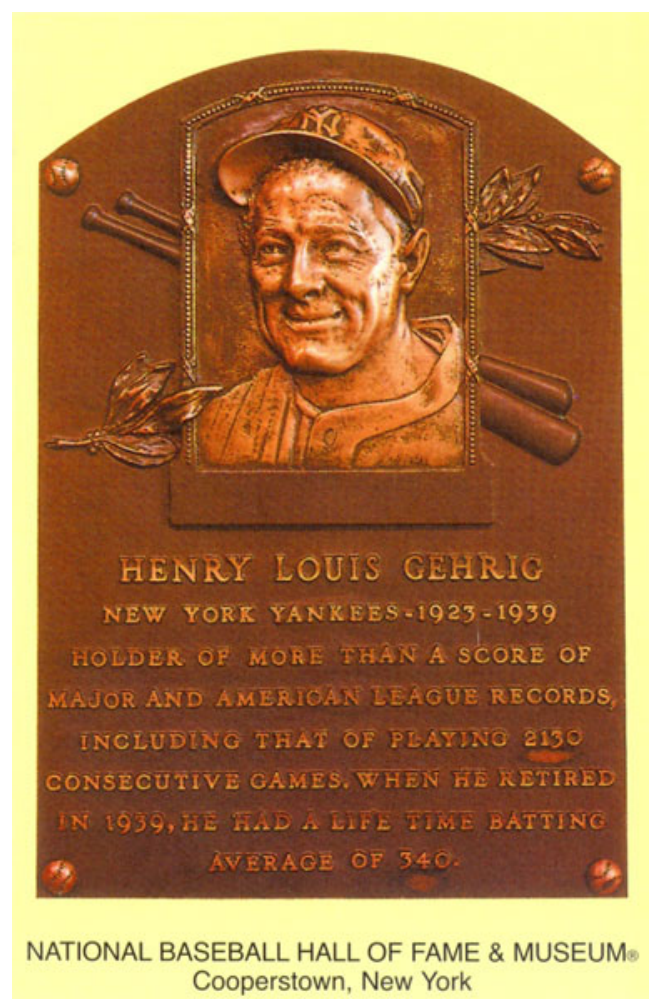

Fig. 1 Metallic photograph of Baseball Legend Henry Lou Gehrig purchased by the editor (Peter L. Pedersen) of this journal (Journal of Bioenergetics and Biomembranes) from the National Baseball Hall of Fame and Museum, Cooperstown, New York. It should not be replicated for distribution, and all requests for a Metallic copy should be made directly to the National Baseball Hall of Fame and Museum

(Vance et al. 2009, ALS6 - OMIM \#608030). A useful review of the genetic complexity of this phenotype is presented by Kunst (2004).

\section{Pathophysiologic studies}

A simple defect in SOD1 activity as an explanation for the changes in ALS appeared unlikely because an SOD1 knockout mutation in the mouse was not associated with a motor defect. Studies of human SOD1 transgenic mutants in mice (e. g. G37R) showed little change in motor function and suggested that a toxic effect of the mutant was important (Borchelt et al. 1994). Subsequently, ultrastructural studies showed abnormal mitochondrial morphology and aggregations in ALS neurons (Siklos et al. 1996; Sasaki and Iwata 1996). Liu et al. (1998) used transgenic mice expressing mutant human SOD1 and found increased free radical production in the spinal cord (but not in the brain). These important observations (as well as many others) emphasized mitochondrial physiology as a central area for study.

The status of intracellular calcium is critical in both neuronal termini and muscle cells. In muscle, calcium is central to coupling excitation and contraction. Following depolarization, calcium entry leads to release of calcium stored in the sarcoplasmic reticulum bathing the myofilament contractile apparatus. Damiano et al. (2006) noted altered calcium uptake in mitochondria from spinal cord neurons of FALS mice. Martin (2011) reviews detailed genetic contributions as well as important aspects of mitochondrial physiology in ALS. In particular, the contributions of apoptosis, calcium transport and reactive oxygen species are described in detail. The value of animal models also is noted. Barrett et al. (2011) review the status of calcium in motor nerve termini. In the normal system, repeated stimulation leads to striking calcium uptake by mitochondria where it is buffered by phosphate (an interaction assisted by an increasingly alkaline environment due to proton extrusion). They show that in mice transgenic for G93A or G85R SOD1 mutations there is defective mitochondrial calcium uptake early following repeated stimulation. Mitochondrial membrane potential is reduced (i.e. depolarized) in response to stimulation (a phenomenon that increases with age). The net effect of this is to reduce total mitochondrial calcium uptake following stimulation. Interestingly, cyclosporin A reduces stimulationinduced membrane depolarization and inhibits the mitochondrial permeability transition pore.

Faes and Callewaert (2011) address the question of a toxic effect of mutant SOD1 in a different system. Recalling earlier evidence for distorted mitochondrial morphology in ALS and ultrastructural evidence for often close apposition between the endoplasmic reticulum (ER) and mitochondria they examine the voltagedependent anion channel 1 (VDAC1) with which mutant SOD1 had been shown to associate. VDAC1 appears multifunctional and also has been isolated from the ER. The underlying notion is that VDAC1 is at least a part of the coupling between mitochondria and the ER and that in ALS the effectiveness of this coupling is reduced. Their study system uses N2a neuroblastoma cells expressing mutant SOD1. They report reduced calcium uptake into mitochondria and increased cytosolic calcium. Cytosolic ATP levels are decreased as well, possibly reducing critical cellular functions.

Another perspective on SOD1 in ALS is provided by Carri and Cozzolino (2011) who evaluate data on SOD1 in mitochondria. They note that the enzyme is mostly found in the intermembrane space but some is in the matrix as well as on the cytoplasmic face of the outer membrane. An important question is how SOD1 reaches the internal spaces since it lacks either an N-terminal or internal targeting sequence. It is likely that the copper chaperone CCS enters the mitochondrion first followed by SOD1 through the Erv1/Mia40 oxidative folding mechanism. (SOD1 has 4 cysteine residues.) The level of SOD1 mutant protein is increased in mitochondria. This could either reflect 
increased transport in or trapping inside. In the latter situation, alternative folding of the mutant protein could decrease its mobility once inside and subjected to oxidation. Such SOD1 accumulation (and likely dysfunction) could then lead to altered mitochondrial function, altered structure and even apoptosis. An additional possibility is that this could cause altered transcription and/or mRNA splicing of a select group of proteins essential for neurons.

The centrality of mitochondrial dysfunction in ALS now opens several pathways for more detailed analysis. To date, no successful therapeutic strategies have emerged but clarification of details in this important subset of individuals (those whose ALD reflects SOD1 mutation[s]) is a promising area for further study.

\section{References}

Andersen PM, Nilsson P, Ala-Hurula V, Keranen ML, Tarvainen I, Haltia T, Nilsson L, Binzer M, Forsgren L, Marklund SL (1995) Nature Genet 10:61-66

Barrett EF, Barrett JN, David G (2011) J Bioenerg Biomem

Borchelt DR, Lee MK, Slunt HS, Guarnieri M, Xu ZS, Wong PC, Brown RH Jr, Price DL, Sisodia SS, Cleveland DW (1994) Proc Natl Acad Sci USA 91:8292-8296

Carri MT, Cozzolino M (2011) J Bioenerg Biomem
Cudkowicz ME, McKenna-Yasek D, Sapp PE, Chin W, Geller B, Hayden DL, Schoenfeld DA, Hosler BA, Horvitz HR, Brown RH (1997) Ann Neurol 41:210-221

Damiano M, Starkov AA, Petri S, Kipiani K, Kiaei M, Mattiazzi M, Flint BM, Manfredi G (2006) J Neurochem 96:1349-1361

Elden AC, Kim HJ, Hart MP, Chen-Plotkin AS, Johnson BS, Fang X, Armakola M, Geser F, Greene R, Lu MM, Padmanabhan A, Clay-Falcone D et al (2010) Nature 466:1069-1075

Faes L, Callewaert G (2011) J Bioenerg Biomem

Ganzini L, Johnston WS, McFarland BH, Tolle SW, Lee MA (1998) N Engl J Med 339:967-973

Kunst CB (2004) Am J Hum Genet 75:933-947

Liu R, Althaus JS, Ellerbrock BR, Becker DA, Gurney ME (1998) Ann Neurol 44:763-770

Martin LJ (2011) J Bioenerg Biomem. doi:10.1007/s10863-011-9395-y

Piemonte and Valle d'Aosta Register for Amyotrophic Lateral Sclerosis (2001) Neurology 56: 239-244

Rose DR, Siddique T, Patterson D, Figlewicz DA, Sapp P, Hentati A, Donaldson D, Goto J, O'Regan JP, Deng H-X, Rahmani Z, Krizus A et al (1993) Nature 362:59-62

Sasaki S, Iwata M (1996) Neurosci Lett 204:53-56

Siddique T, Figlewicz DA, Pericak-Vance MA, Haines JL, Rouleau G, Jeffers AJ, Sapp P, Hung W-Y, Bebout J, McKenna-Yasek D, Deng G, Horvitz HR, Gusella JF, Brown RH Jr, Roses AD (1991) N Engl J Med 324:1381-1384

Siklos L, Engelhardt J, Harati Y, Smith RG, Joo F, Appel SH (1996) Ann Neurol 39:203-216

Vance C, Rogelj B, Hortobagyi T, De Vos KJ, Nishimura AL, Sreedharan J, Hu X, Smith B, Ruddy D, Wright P, Ganesalingam J, Williams KL et al (2009) Science 323:1208-1211 